\title{
Reduction of coronary artery multi-slice computed tomographic radiation and maintained image interpretability by parameter optimization: the multicenter RAMBO study
}

D. PESENTI ROSSI ${ }^{1}$, G. GIBAULT-GENTY ${ }^{1}$, J.-L. GEORGES ${ }^{1}$, R. CONVERS ${ }^{1}$, N. BARON ${ }^{1}$, S. CHAYEB ${ }^{1}$, L. NAY ${ }^{1}$, G. GALUSCAN ${ }^{1}$, C. CHARBONNEL ${ }^{1}$,

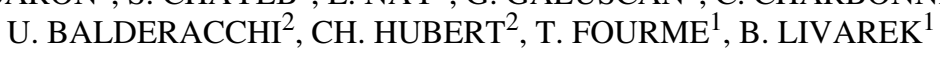

(Manuscript received 1st July 2012, accepted 26 September 2012)

ABSTRACT Multi-slice computed tomography (MSCT) has proven in several studies to have a high diagnostic accuracy for the detection or exclusion of coronary artery disease. A major concern with coronary MSCT, however, is the associated radiation exposure of patients. Recent studies suggest that use of a 64-slice scanner is associated with a non-negligible lifetime attributable risk of cancer. Several strategies can be used to reduce patient exposure in coronary MSCT. The purpose of this multicenter study was to investigate the effects of the adjustment of tube voltage and current on radiation dose and image interpretability. MSCT with retrospective ECG gating was performed in 315 patients. The dose-length product (DLP) in the patients enrolled with the dose reduction protocol resulted in a $36 \%$ overall reduction in the mean radiation dose $(911 \pm 289 \mathrm{mGy} . \mathrm{cm})$ compared with the standard protocol $(1427 \pm$ 226 mGy.cm, $p<0.001$ ). Nevertheless, image interpretability was maintained. This study on coronary MSCT demonstrates that the radiation dose can be significantly reduced by parameter optimization, with maintained image interpretability.

Keywords: computed tomography / radiation dose / cardiac imaging

\section{Introduction}

Since the 1970s, the development of imaging techniques using ionizing radiation has resulted in considerable progress in the diagnosis, understanding of the pathophysiology, and treatment of valvular, ischemic and heart rhythm diseases. The appropriation of these techniques by interventional or non-interventional cardiologists, most often untrained in radiation protection, has led to exposing both patient and operator to significant doses of radiation, without a real quality control

Department of Cardiology, Versailles Hospital, 177 rue de Versailles, 78150 Le Chesnay, France.

Department of Radiology, Versailles Hospital, 177 rue de Versailles, 78150 Le Chesnay, France.

* e-mail: david.pesentirossi@gmail.com 
of the practices. A recent editorial (Georges et al., 2011), "Controlling the radiation dose received by patients undergoing cardiac imaging", emphasizes the need to follow the three steps of radiation protection suggested by the International Commission on Radiological Protection (ICRP, 2007): justification, optimization concerning the patient, and dose limitation.

Multi-slice computed tomography (MSCT) has proven in several studies (Leschka et al., 2005; Pesenti-Rossi et al., 2011; Mollet et al., 2005; Caussin et al., 2006) to have a high diagnostic accuracy for the detection or exclusion of coronary artery disease. A major concern with coronary MSCT, however, is the associated radiation exposure of patients. The number of patients who undergo MSCT coronary angiography is steadily growing, and there is increasing scrutiny of the radiation dose delivered during this examination. Einstein et al. recently demonstrated that radiation exposure from 64-section MSCT coronary angiography is associated with a relatively wide variation in the lifetime attributable risk of cancer in relation to patient age and sex (Einstein et al., 2007). Consideration of radiation protection issues is particularly warranted in young women, who are the most vulnerable to radiation exposure.

Several studies of the radiation exposure associated with coronary MSCT (Hausleiter et al., 2006; Rehani, 2010) have shown large variations, the effective dose (ED) being as high as $30 \mathrm{mSv}$ when not implementing the electrocardiography (ECG) pulsing technique for a dose reduction. Several strategies can be used to reduce patient exposure in coronary MSCT. Most cardiac MSCT scans are performed using the retrospective ECG gating technique, which indicates that the volume data is acquired during the entire cardiac cycle within a single breath-hold helical scan. Modern CT scanners include tube voltages of $120 \mathrm{kV}$ or $140 \mathrm{kV}$, reflecting the settings that most often result in adequate image quality. However, cardiac CT acquisition with a voltage of $100 \mathrm{kV}$, or even lower, is possible and has been suggested as an effective means to reduce the radiation dose in cardiac CT imaging. Otherwise, there is a linear relationship between adjustment of the tube current and the subsequent radiation dose change.

Therefore, the purpose of this multicenter study was to investigate the effects of a dose reduction protocol, by adjusting the tube voltage and current to the patient's weight, on radiation dose and image interpretability.

\section{Material and methods}

\subsection{Study population}

MSCT with retrospective ECG gating was performed in 315 consecutive patients. During the first period, 165 consecutive patients were assigned to a standard 
TABLE I

Population characteristics.

\begin{tabular}{ll}
\hline Patients $(n)$ & 315 \\
\hline Women $(n / \%)$ & $98(31.1 \%)$ \\
\hline Family history of coronary disease $(\%)$ & $76(24 \%)$ \\
\hline Nicotine abuse $(\%)$ & $81(25.8 \%)$ \\
Hypertension $(\%)$ & $103(32.8 \%)$ \\
\hline Dislipidaemia $(\%)$ & $108(34.5 \%)$ \\
\hline Diabetes $(\%)$ & $77(13.8 \%)$ \\
\hline Ages (mean values \pm SD) & $58.7 \pm 12.5 \mathrm{years}($ range, $29-81 \mathrm{years})$ \\
\hline Body mass index (mean values $\pm \mathrm{SD})$ & $24.9 \pm 3.4 \mathrm{~kg} / \mathrm{m}^{2}\left(\right.$ range, $\left.17.2-34.7 \mathrm{~kg} / \mathrm{m}^{2}\right)$ \\
\hline
\end{tabular}

scanning protocol and during the second period, 150 consecutive patients were assigned to a dose reduction protocol with adjustment for patient weight. The institutional review board approved the study, and all included patients gave informed consent. Only those patients with a sinus rhythm were included. Exclusion criteria were substantial renal dysfunction, defined as a serum creatinine level higher than $150 \mu \mathrm{mol} / \mathrm{L}$, and known allergy to contrast material.

Our study population comprised 315 patients (overall mean age, $58.7 \pm 12.5$ years [standard deviation]; age range, 29-81 years): 217 men and 98 women, with a mean body mass index (BMI) of $24.9 \pm 3.4 \mathrm{~kg} / \mathrm{m}^{2}$ (range, $17.2-34.7 \mathrm{~kg} / \mathrm{m}^{2}$ ). The demographic and main clinical data are summarized in Table I. The indications were consistent with the recommendations set by the French Society of Cardiology (Caussin, 2009; Pernès et al., 2009). Reasons for referral were atypical chest pain in patients with low to intermediate coronary artery disease combined with inconclusive ECG or stress test results (163 patients), dilated cardiomyopathy (19 patients), left bundle branch block (6 patients), coronary stent evaluation (12 patients), coronary artery bypass graft assessment (13 patients), syncope (30 patients) or others ( 72 patients). 165 were examined with a standard protocol, 150 were examined with a dose reduction protocol.

\subsection{CT scanning protocol}

In patients with heart rates $>70$ beats/min, a beta-blocker (Metoprolol $100 \mathrm{mg}$ ) was administered orally $60 \mathrm{~min}$ before the MSCT. In the presence of contraindications for a beta-blocker or an unsatisfactory lowering of the heart rate, the scan was performed at even greater heart rates. Before scanning, the patients received a single $0.30-\mathrm{mg}$ dose of isosorbide dinitrate (Natispray ${ }^{\circledR}$, Procter \& Gamble Pharmaceuticals) sublingually. 


\section{Scanning protocols}

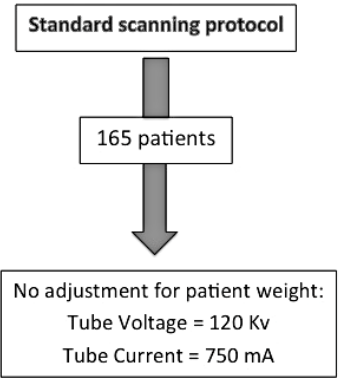

ube Current $=750$

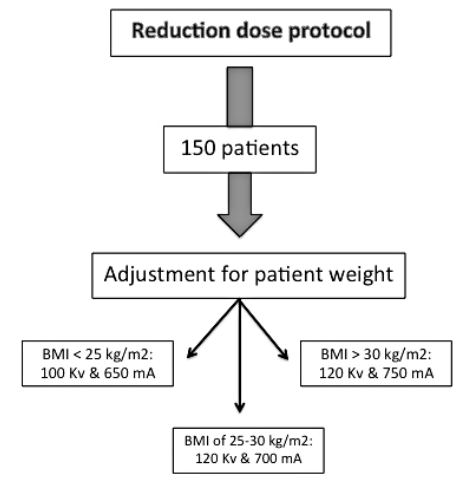

Figure 1 - Study design.

The MSCT angiography was performed using a 64-slice scanner (VCT Lightspeed 64; GE Healthcare, Milwaukee, Wisc., USA) in the Rambouillet and Versailles Hospitals. A bolus of $80 \mathrm{ml}$ of contrast agent (Iopamiron $370^{\circ}$, Bracco, Italy) was injected intravenously using a triphasic injection with manual release of the acquisition during the opacification of the ascending aorta. A saline chaser was used after the contrast bolus. Standard cardiac collimation and slice thickness values were employed for the measurements. The VCT Lightspeed scanner acquires 64 overlapping $0.625-\mathrm{mm}$ slices per rotation. The helical pitch was 0.2 , rotation time was $350 \mathrm{~ms}$, and total breath-hold was about 12 seconds with simultaneous recording of the electrocardiogram (ECG) trace. The acquisition was performed with a retrospective electrocardiogram gating and a tube current modulation. The normal tube current was applied only during the image reconstruction phase (at $40 \%-80 \%$ of the R-R interval), while the tube current was reduced during the systolic phase. Using retrospective ECG gating, the optimal ECG phase providing the best image quality was chosen.

\subsection{Dose reduction protocol}

During the first period, 165 consecutive patients were assigned to a standard scanning protocol involving a tube voltage of $120 \mathrm{kV}$ and $750 \mathrm{~mA}$ (standard protocol, the system settings) without adjustment for patient weight.

During the second period, 150 consecutive patients were assigned to a dose reduction protocol with adjustment for patient weight (Fig. 1): a tube voltage of 
$100 \mathrm{kV}$ when they were of normal weight $\left(<85 \mathrm{~kg}\right.$ or BMI $\left.<25 \mathrm{~kg} / \mathrm{m}^{2}\right)$ and a tube voltage of $120 \mathrm{kV}$ when they were overweight $\left(>85 \mathrm{~kg}\right.$ or BMI $\left.>25 \mathrm{~kg} / \mathrm{m}^{2}\right)$. In addition, the tube current used was $650 \mathrm{~mA}$ when they were of normal weight $\left(<85 \mathrm{~kg}\right.$ or BMI $\left.<25 \mathrm{~kg} / \mathrm{m}^{2}\right)$, a tube current of $700 \mathrm{~mA}$ was used when they were overweight $\left(85-100 \mathrm{~kg}\right.$ or BMI of $\left.25-30 \mathrm{~kg} / \mathrm{m}^{2}\right)$ and a tube current of $750 \mathrm{~mA}$ was used when they were obese $\left(>100 \mathrm{~kg}\right.$ or BMI $\left.>30 \mathrm{~kg} / \mathrm{m}^{2}\right)$.

For the two protocols, the adjustment of the $z$-axis coverage (craniocaudal) was similar, using the scout images acquired without injection. The top mark was the highest located coronary segment, usually the left anterior descending artery, and as a lower mark, the posterior descending artery.

\subsection{Coronary MSCT reconstruction and analysis}

CT data were transferred to an off-line image analysis workstation: ADW, CardiQ Xpress (GE Healthcare, Milwaukee, Wisc., USA). Two blinded experienced observers (3 or more years of CT coronary angiography training) independently interpreted the images. Interpretations were performed with axial data sets, maximum intensity projections, or curved multiplanar reformations at the discretion of the reader. Per-patient and per-artery interpretability required that every coronary artery segment present (modified 16-segment American Heart Association model) be judged interpretable regardless of size. If any segment was not interpretable, the corresponding artery and all of the patient's images were deemed not interpretable.

\subsection{Estimation of radiation dose}

The effective dose (ED) of MSCT can be estimated by a method proposed by the European Working Group for Guidelines on Quality Criteria in CT (Bongartz et al., 2004). This method is commonly used in the clinical literature (Einstein et al., 2010) and has been shown to be reasonably robust and consistent for estimating the effective dose. The effective dose is derived from the product of the DLP by a correction factor $(k)$ for the chest as the investigated anatomic region. This correction factor $[k=0.014 \mathrm{mSv} /(\mathrm{mGy} . \mathrm{cm})-1]$ is averaged between male and female models.

\subsection{Statistical analysis}

Continuous variables were expressed as mean values \pm standard deviation and nominal variables as counts and percentages. Comparison between different groups was calculated using the $t$ test. A $p$ value $<0.05$ was regarded as statistically significant. 
TABLE II

Demographic and clinical data.

\begin{tabular}{|c|c|c|c|}
\hline Demographic and clinical data & Standard protocol & Reduction dose protocol & $\mathrm{p}$ \\
\hline Patients (n) & 165 & 150 & \\
\hline Ages (range) & $\begin{array}{l}57.5 \pm 13.4 \text { years [standard } \\
\text { deviation] } \\
\text { (range, 29-81 years) }\end{array}$ & $\begin{array}{l}58.6 \pm 12.4 \text { years [standard } \\
\text { deviation] } \\
\text { (range, } 31-79 \text { years) }\end{array}$ & 0.86 \\
\hline Women (n) & 55 & 43 & 0.35 \\
\hline Body mass index (range) & $\begin{array}{l}24.8 \pm 3.0 \mathrm{~kg} / \mathrm{m}^{2} \\
\left(\text { range, } 17.2-34.7 \mathrm{~kg} / \mathrm{m}^{2}\right)\end{array}$ & $\begin{array}{l}25.2 \pm 3.2 \mathrm{~kg} / \mathrm{m}^{2} \\
\left(\text { range, } 17.6-33.6 \mathrm{~kg} / \mathrm{m}^{2}\right)\end{array}$ & 0.31 \\
\hline Heart rate (range) & $\begin{array}{l}64.1 \pm 7.2 \mathrm{bpm} \\
(\text { range, } 49-85 \mathrm{bpm})\end{array}$ & $\begin{array}{l}62.8 \pm 7.2 \mathrm{bpm} \\
(\text { range, } 46-82 \mathrm{bpm})\end{array}$ & 0.1 \\
\hline \multicolumn{4}{|l|}{ Current indications } \\
\hline Atypical chest pain & 79 & 84 & 0.16 \\
\hline Dilated cardiomyopathy & 11 & 8 & 0.61 \\
\hline Left bundle branch block & 4 & 2 & 0.47 \\
\hline Coronary stent evaluation & 5 & 7 & 0.06 \\
\hline $\begin{array}{l}\text { Coronary artery bypass graft } \\
\text { assessment }\end{array}$ & 7 & 6 & 0.9 \\
\hline Syncope & 19 & 11 & 0.2 \\
\hline Others & 40 & 32 & 0.5 \\
\hline
\end{tabular}

\section{Results}

The study cohort consisted of 315 patients ( $68.9 \%$ men, $31.1 \%$ women; mean age, $58.7 \pm 12.5$ [SD] years) who underwent consecutive retrospectively ECGtriggered coronary MSCT examinations at two centers. In this study, 165 were examined with a standard protocol, and 150 were examined with a dose reduction protocol. The median heart rate for the study population was 63 beats $/ \mathrm{min}$. There was no significant difference in age $(p=0.74)$, body mass index $(p=0.31)$, heart rate $(p=0.10)$, gender distribution $(p=0.35)$ or the current indications among the two patient groups. These data are summarized in Table II.

\subsection{Radiation dose}

The dose-length product (DLP) of the standard protocol (1427 $\pm 226 \mathrm{mGy} . \mathrm{cm})$ was significantly higher than that of the dose reduction protocol $(911 \pm 289$ mGy.cm, $p<0.001)$. The estimated effective radiation dose was, respectively, $19.9 \mathrm{mSv}$ vs. $12.7 \mathrm{mSv}$. These data are summarized inTable III. 
TABLE III

Radiation dose.

\begin{tabular}{llll}
\hline \multicolumn{1}{c}{ Radiation dose } & \multicolumn{1}{c}{ Standard protocol } & \multicolumn{1}{c}{ Reduction dose protocol } & \multicolumn{1}{c}{$p$} \\
\hline Dose-length product (mGrays.cm) & $\begin{array}{l}1427 \pm 226 \text { mGrays.cm } \\
\text { (range, 985-2543) }\end{array}$ & $\begin{array}{l}911 \pm 289 \text { mGrays.cm } \\
\text { (range, 526-1757) }\end{array}$ & $<0.001$ \\
Mean estimated effective dose $(\mathrm{mSv})$ & $19.9 \mathrm{mSv}$ & $12.7 \mathrm{mSv}$ & \\
\hline
\end{tabular}

\subsection{Image interpretability}

There were no differences in per-patient $(p=0.35)$ or per-artery $(p=0.71)$ image interpretability between the two groups (Tab. IV).

TABLE IV

Image interpretability.

\begin{tabular}{lccl}
\hline Image interpretability & Standard protocol & Reduction dose protocol & $p$ \\
\hline Image interpretability rate per-artery & $92 \%$ & $91 \%$ & 0.71 \\
Image interpretability rate per-patient & $89.1 \%$ & $88 \%$ & 0.35 \\
\hline
\end{tabular}

\section{Discussion}

Recent studies suggest that use of 64-slice MSCT is associated with a nonnegligible lifetime attributable risk of cancer (Zanzonico et al., 2006). Lifetime cancer risk estimates for standard cardiac scans varied from 1 in 143 for a 20-yearold woman to 1 in 3261 for an 80-year-old man (Einstein et al., 2007). The rapid increase in multidetector CT examinations performed in patients with heart conditions has raised concern about the increasing radiation exposure to patients. A new cardiac MSCT generation with prospective pulse acquisition is associated with low radiation exposure but currently, the majority of scanners in operation have an unpulsed retrospective acquisition. With 64-slice retrospectively ECGgated cardiac CT, the effective radiation dose averages approximately $20 \mathrm{mSv}$ (Hausleiter et al., 2006). Therefore, several techniques to reduce the radiation exposure have been evaluated and include ECG-based tube current modulation, tube voltage reduction and attenuation-based tube current modulation. In our study, we investigated a dose reduction protocol with adjustment of the tube current and voltage to the patient's body mass index.

The effective dose in the patients enrolled with the dose reduction protocol resulted in a $36 \%$ overall reduction in the mean effective radiation dose $(12.7 \mathrm{mSv})$ compared with the standard protocol $(19.9 \mathrm{mSv})$. Nevertheless, image quality was maintained. 
There were limitations to our study. First, several strategies can be used to reduce patient exposure in coronary MSCT (Torres et al., 2010; Rehani, 2010). Prospective ECG triggering and iterative reconstruction have been confirmed to be the most efficient techniques for radiation dose reduction in cardiac MSCT (Schoenhagen, 2008; Leipsic et al., 2010). Therefore, our method is mainly available for cardiac MSCT using the retrospective ECG gating technique. Nonetheless, in addition to these two techniques, the adjustment of the tube voltage and current to the patient's weight allows an additional dose reduction. Second, the per-artery image interpretability rate was obtained at $92 \%$ with the standard protocol and $91 \%$ with the dose reduction protocol without significant differences among the two groups. In recent studies (Stolzmann et al., 2008; Hausleiter et al., 2010), diagnostic image quality was obtained for $97.9 \%$ of coronary segments but patients who had obesity were excluded (BMI $>30 \mathrm{~kg} / \mathrm{m}^{2}$ ). However, the aim of our study was to assess the dose reduction protocol under real-life conditions, including all patients. Patients were not included based upon their body mass index. BMI ranged between 17.2 and $34.7 \mathrm{~kg} / \mathrm{m}^{2}$.

\section{Conclusion}

Many techniques and strategies are now available for dose reduction in cardiac MSCT. Nevertheless, in the daily practice of coronary MSCT angiography, lowering the tube current and voltage is a valuable tool for a substantial reduction in the effective radiation dose at no cost to image interpretability.

\section{REFERENCES}

Bongartz G., Golding S.J., Jurik A.G., et al. (2004) European Guidelines for Multislice Computed Tomography: Appendix C, Funded by the European Commission, March 2004.

Caussin C. (2009) Positioning coronary multislice computed tomography as a pertinent tool for cardiac exploration, Arch. Cardiovasc. Dis. 102 (10), 673-675.

Caussin C., Larchez C., Ghostine S., et al. (2006) Comparison of coronary minimal lumen area quantification by sixty-four-slice computed tomography versus intravascular ultrasound for intermediate stenosis, Am. J. Cardiol. 98, 871-876.

Einstein A.J., Henzlova M.J., Rajagopalan S. (2007) Estimating risk of cancer associated with radiation exposure from 64-slice computed tomography coronary angiography, JAMA 298 (3), 317-323.

Einstein A.J., Elliston C.D., Arai A.E., et al. (2010) Radiation dose from single-heartbeat coronary CT angiography performed with a 320-detector row volume scanner, Radiology 254 (3), 698-706.

Georges J.L., Pesenti-Rossi D., Livarek B. (2011) Controlling the radiation dose received by patients undergoing cardiac imaging, Future Cardiol. 7 (1), 1-5.

Hausleiter J., Meyer T., Hadamitzky M., et al. (2006) Radiation dose estimates from cardiac multislice computed tomography in daily practice: impact of different scanning protocols on effective dose estimates, Circulation 113 (10), 1305-1310. 
Hausleiter J., Martinoff S., Hadamitzky M., et al. (2010) Image quality and radiation exposure with a low tube voltage protocol for coronary CT angiography results of the PROTECTION II Trial, JACC Cardiovasc. Imag. 3 (11), 1113-1123.

ICRP publication 103 (2007) The 2007 Recommendations of the International Commission on Radiological Protection, Ann. ICRP 37 (2-4).

Leipsic J., Labounty T.M., Heilbron B., et al. (2010) Adaptive statistical iterative reconstruction: assessment of image noise and image quality in coronary CT angiography, Am. J. Roentgenol. 195 (3), 649-654.

Leschka S., Alkadhi H., Plass A., et al. (2005) Accuracy of MSCT coronary angiography with 64-slice technology: first experience, Eur. Heart J. 26, 1482-1487.

Mollet N.R., Cademartiri F., van Mieghem C.A., et al. (2005) High-resolution spiral computed tomography coronary angiography in patients referred for diagnostic conventional coronary angiography, Circulation 112, 2318-2323.

Pernès J.M., Sirol M., Chabbert V., et al. (2009) Current indications for cardiac CT, J. Radiol. 90 (9Pt2), 1123-1132.

Pesenti-Rossi D., Chouli M., Gharbi M., et al. (2011) Coronary aorto-ostial analysed by Multi-Slice Computed Tomography: A new tool for PCI?", EuroIntervention 6 (6), 717-721.

Rehani M.M. (2010) Radiation protection in newer imaging technologies, Radiat. Prot. Dosim. 139 (1-3), 357-362.

Schoenhagen P. (2008) Back to the future: coronary CT angiography using prospective ECG triggering, Eur. Heart J. 29, 153-154.

Stolzmann P., Leschka S., Scheffel H., et al. (2008) Dual-source CT in step-and-shoot mode: noninvasive coronary angiography with low radiation dose, Radiology 249 (1), 71-80.

Torres F.S., Crean A.M., Nguyen E.T., et al. (2010) Strategies for radiation-dose reduction and imagequality optimization in multidetector computed tomographic coronary angiography, Can. Assoc. Radiol. J. 61 (5), 271-279.

Zanzonico P., Rothenberg L.N., Strauss H.W. (2006) Radiation exposure of computed tomography and direct intracoronary angiography: risk has its reward, J. Am. Coll. Cardiol. 47 (9), 1846-1849. 